\title{
From The Trash to High Couture: How Wearable Food Waste is Transforming the Textile Industry In Line with the Agenda 2030
}

\author{
Sara Cavagnero ${ }^{1 *}$ and Luca Lazzarini ${ }^{2}$ \\ ${ }^{1}$ Northumbria University, UK \\ ${ }^{2} I P C-I G$ - International Policy Centre for inclusive Growth, Brazil
}

*Corresponding author: Sara Cavagnero, Department of Business and Law, Northumbria University, UK

Received Date: February 25, 2020

Published Date: June 01, 2020

\begin{abstract}
The textile and food industries seem worlds apart. One is focused on trend-setting and design, the other on growing, processing, manufacturing and distributing food, from the farm to retail shops and restaurants. For a long time, synergies and trade-offs between these sectors have been overlooked. More recently, however, the two industries came together to tackle common challenges, unleashing innovative and sustainable solutions.

Through a theoretical and empirical analysis, this paper investigates emerging methods of treating food waste and by-products to produce fibres, arguing that cross-industry collaboration can lead to regenerative impacts for the benefit of nature, society, and economy. Orange Fibre, Piñatex, S. Café are among the case studies scrutinised to illustrate the advantages related to edible innovations. Turning waste into a resource is essential to increase efficiency and close the loop in a circular economy, improve waste management practices, and limit the use of landfilling, in line with the EU Framework Directive on waste and SDG 12.3. Furthermore, recycled and innovative fibres do not require any extra farmland, water, fertilisers or pesticides to be produced.
\end{abstract}

Fostering cross-industry collaboration, pursuant to SDG 17, can also serve as a source of brand differentiation. As more-sustainable solutions seem increasingly attractive for a growing customer base, partnerships may open up new opportunities for business, despite the pressures of resource scarcity.

\section{Introduction}

The world is currently implementing the Agenda 2030 adopted by the UN in 2015 (United Nations, 2015). With unprecedented resources constraints and just 10 years left to the 2030 deadline, the achievement of the SDGs requires immediate and accelerated actions, as well as collaborative partnerships among stakeholders at all levels to go beyond a business as usual scenario. The ways societies - at individual, corporate, national, and international levels - translate this global blueprint into actions vary among the world's regions, but it appears that there are still major challenges to be faced. Indeed, the rate of global progress is not keeping pace with the ambitions of the 17 Sustainable Development Goals (SDGs), and no country is on track to meet all the targets by 2030 in terms of financial resources and political support [1]. In addition, the growing pressure on the planetary boundaries, as defined by the Stockholm Resilience Center, is generating continuing deterioration of the biophysical environment - threatening largescale ecosystems collapse [2,3].

Globally, millions of workers, communities, and businesses are involved directly and indirectly in the complex and fragmented food and apparel value chains. Albeit being considered as worlds apart, garments and food share many similarities: they are both 
commodity products, which have origins in agricultural systems food in an almost total way, while natural fibers make up $27 \%$ of the global supply [4]. Apparel and food are typically manufactured from little valued and indiscriminately sourced raw materials involving hard labour at the beginning of the supply chain, and intensive commercialization at the end [5]. The price of both food and clothing has reduced over the last twenty years, while the purchased volume has increased [6]. Over-consumption, as well as linear models for producing, distributing, and disposing goods characterizes both sectors $[7,8]$.

Acting upon the sectors' vast sustainability challenges and risks in a concerted manner would contribute to the achievement of several SDGs, such as ending poverty, adapting to climate change and fostering inclusive growth. The table in Figure 1 aims at highlighting the linkages and trade-offs of acting towards the achievement of nine SDGs, where the industries have the most direct social and environmental footprint. Partnership is a cross cutting issue across these clusters.
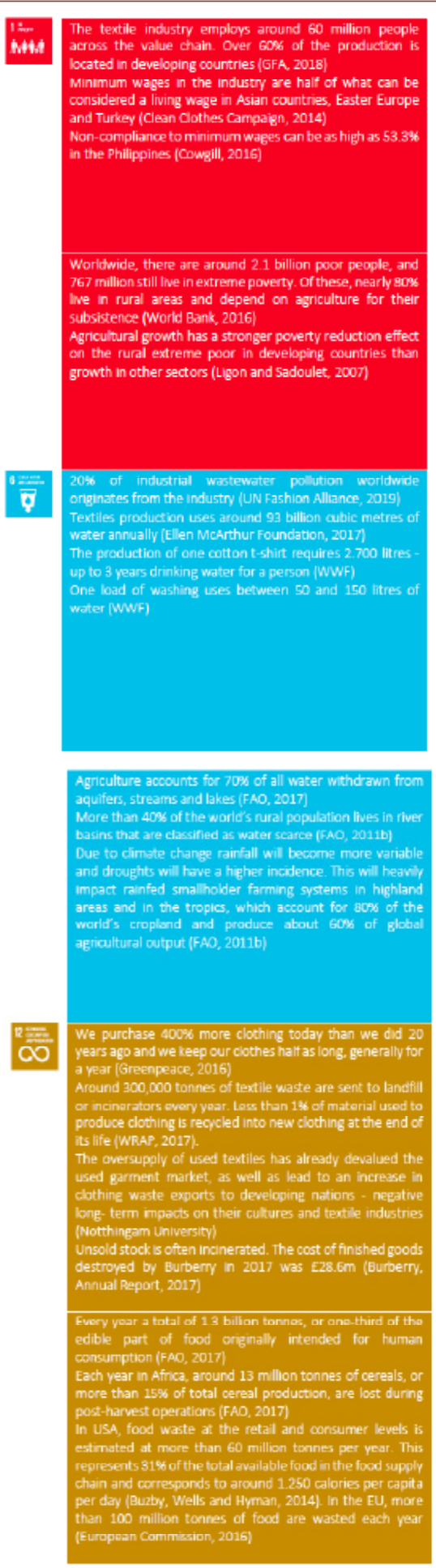
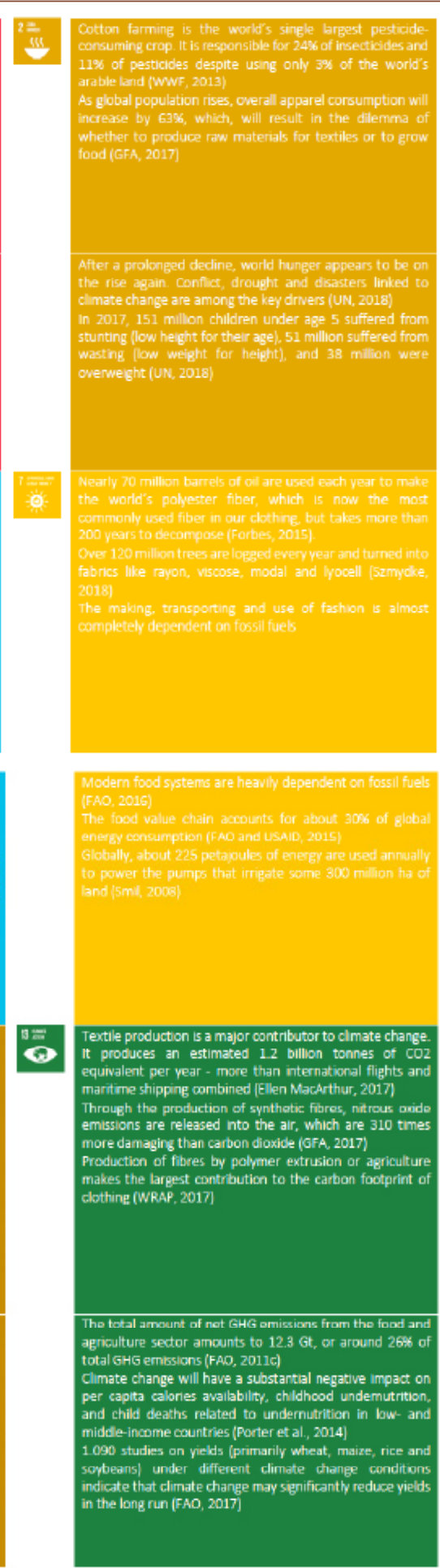
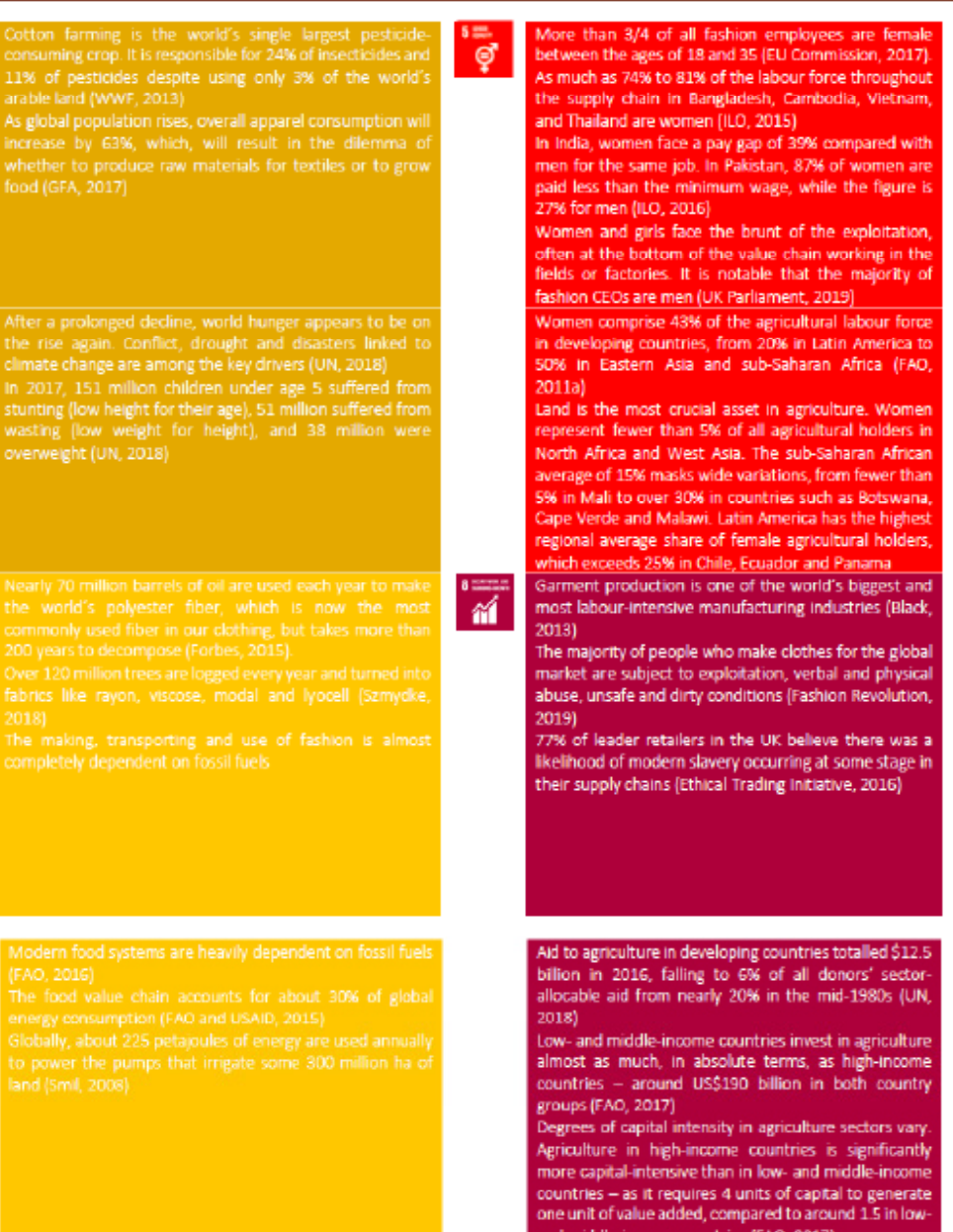

5:-

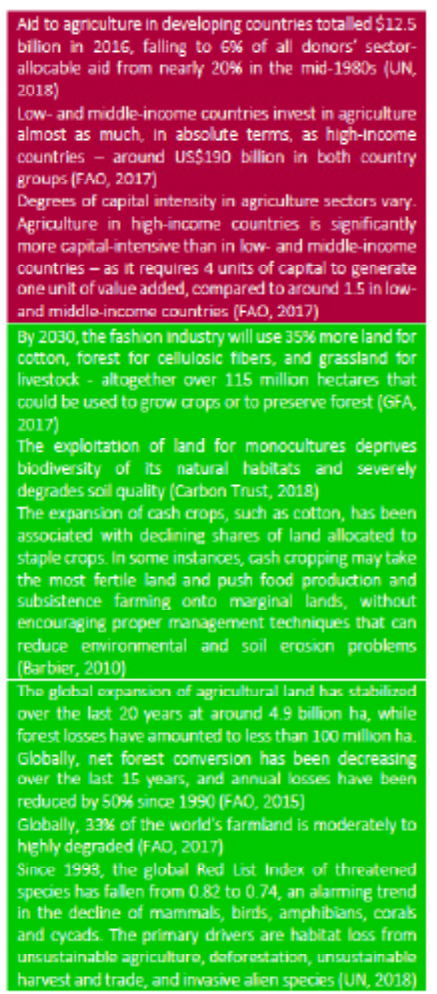

Figure 1: Overview of the main impacts of the food and fashion industries, in relation to the SDGs. 
For the sake of clarity, it is relevant to notice that although the terms are often used as synonyms, the fashion and textile industry do not coincide. The latter commonly concerns the production of yarn, textiles and fabrics, while the former (also referred to as the garment or apparel industry) relates to the production of clothing. The textile sector also includes household and technical/ industrial textiles, while the fashion industry encompasses shoes, bags, jewellery and other accessories $[9,10]$. Such considerations are relevant to bear in mind when examining data, as it is often difficult to distinguish the garment and textile sectors within their complex, multi-layered and fragmented supply chains, although the second is broader and includes - among the others - home ware and bedding [11]. Another important consideration is that estimates are inconsistent, as no standard method for calculations of either the environmental or social impact has been accepted in the industry. However, for sustainability assessment to be successful, reliable, timely and granular data are needed to emphasise where the industry is making progress and where it is falling behind.

System Thinking: Leveraging Interactions Between the Food and Textile Industries

Under pressure from investors, employees, civil society, consumers, and other stakeholders to become more sustainable, the two sectors are starting to recognize the business opportunities inherent in cross-industry collaboration, in line with SDG 17. However, finding efficient and effective means of addressing negative externalities while taking advantage of synergies will require the implementation of a systematic and holistic approach.

This is already partially happening in the agricultural and food sector with a progressive shift towards a food system approach: in 2017 the Committee on World Food Security (CFS) embarked on a multi-stakeholder policy convergence process which will lead to the development of Voluntary Guidelines on Food Systems and Nutrition. Well-known methods like the value chain development and the market systems approach are deemed to be, in certain instances, too narrow. The former evaluates how value is generated and secured not only by producers, but also by other stakeholders i.e. workers, governments and consumers - with a view to improve the value chain efficiency through systemic analysis and integrated interventions. Nonetheless, this approach focuses on one particular commodity, often neglecting the synergies and trade-offs with other food value chains. Similarly, the market systems approach considers market linkages to address constraints affecting multiple value chains but it is usually limited to one market [12]. The food system approach is instead a wider concept and takes into account all the subsystems - e.g. input supply, farming, waste management, etc. - of a given food system as well as their interactions with other key systems - e.g. energy, trade, health, etc. Food systems also add an overall societal and environmental perspective by considering crucial subjects as food security, health, nutrition, employment, research, education, protection of the natural environmental, tradeoffs between the multiple objectives of agriculture (food, feed, fuel and fibre) and so on. It thus encompasses political, economic, social and environmental dimensions.

In this regard, the textile and fashion sector seem to lag behind, as the "cradle-to-grave" impact of a product is not being comprehensively evaluated yet. Life Cycle Assessment (LCA), a globally accepted and product-oriented method for analysing environmental impacts of a good's entire life cycle, including raw material extraction and processing, product manufacture, distribution, use, disposal and recycling [13], is being implemented only by a few brands, notably by the Kering Group through the Environmental Profit and Loss (EP\&L) or by Reformation's RefScale. When it comes to social issues, comprehensive evaluations are even less widespread. The closest tool to LCA is the Social Life Cycle Assessment (S-LCA), which is quite problematic in terms of data collection [14]. Indeed, regardless S-LCA's quantitative nature, some social issues like health and well-being are difficult to measure against given benchmarks and many indicators depict circumstances related to the manufacturing facilities rather than the product itself, which producers are much more hesitant to reveal.

All in all, the adoption of a systemic approach appears a challenging but highly desirable outcome to shed light on nonlinear processes in the textile and fashion industry, and on possible trade-offs between activities and policy objectives. Systemic thinking also broadens the perspective when seeking solutions for the root causes of problems such as labour and natural resources exploitation, acknowledging interactions not only within the industry but also across different sectors, ultimately linking with, and integrating into, innovative and more sustainable value chains.

\section{Addressing Common Challenges to Secure Long-Term Sustainable Outcomes}

Implementing collaborative programs based on a systemic thinking approach enables companies to make significant progress in a relatively short amount of time. Benefitting from key learning's, expertise, and best practices generated by frontrunners, companies can enhance their performance in environmental as well as social areas, while generating proof-points supporting the business case for sustainability.

In the fashion industry, there is a strong push to make every phase of production more sustainable. In particular, following alarming warnings concerning rising costs of materials as well as increased consumer demand for more sustainable products, major maisons, companies in the mid-price segment and, lately, even fast fashion brands, are adjusting their business models and investing in innovation [15]. Thanks to the increased visibility connected to their own sustainability performance, companies have started to take specific actions targeting their input materials, and finding less resource-intensive fabrics is now considered as a priority [16].

The harvesting and sourcing of natural and synthetic fibers, as well as their processing, are responsible for a large share of 
textiles' environmental footprint [17] and consume considerable amounts of resources that are also at the core of agricultural activities. Cellulose-based or plant-based fibers, such as cotton, viscose, and lyocell, account for a third of all textile fibers. Despite being renewable, biodegradable, and mechanically recyclable, such fibres consume large amounts of water and chemicals, especially conventional cotton farming and processing $[18,19]$. Animal fibers, such as leather, wool, or silk, entail both ethical issues as well as significant environmental footprint. On the one hand, brands are confronted with an increasing number of customers demanding guarantees for animal welfare. On the other hand, animal fibers are directly linked to degradation of fertile land, decline in biodiversity due to livestock overgrazing and overstocking, and high release of methane [20]. Synthetic fibers, such as polyester (over half of the total textile fiber production), nylon, and acrylic, require less water and land than cellulose fibers and are more durable. However, their production depends on oil feedstock and is very energy-intensive [21]. In addition, these fibers are not biodegradable and heavily pollutant. It is estimated that approximately half a million tonnes of plastic microfibers shed during the washing of plastic-based textiles end up in the ocean every year. One load of laundry of polyester clothes can discharge 700.000 micro plastic, which release toxins into the environment and can end up in human food chain [22].

At the same time, a stark contrast currently exists in the global food system. According to FAO [23] nearly 821 million people were undernourished - i.e. facing chronic food deprivation - in 2017, and for the third year in a row, global hunger is rising instead of decreasing. Moreover, FAO, IFAD and WFP [24] consider that in a 'business as usual' scenario 637 million people will be undernourished in low- and middle-income countries by 2030: a figure that significantly exceeds previous projections and that, according to the same report, would entail not fulfilling the SDG 2 target of eradicating hunger by the same year. Yet, there is sufficient capacity in the world to produce enough food to feed everyone adequately. Moreover, every year, about 670 million tonnes of food are lost or wasted in high-income countries, and 630 million tonnes in low- and middle-income countries - a total of 1.3 billion tonnes, or one-third of the edible food originally intended for human consumption [25].

Different definitions are being, and have been used to describe food loss and waste (FLW). As a result, in 2014 the Food and Agriculture Organization (FAO) of the United Nations proposed a common definition within the "Global Initiative on Food Loss and Waste Reduction". Food loss is defined as the "decrease in quantity or quality of food", whereas food waste is a sub-component of food loss and refers "to the removal from the food supply chain of food which is fit for consumption, by choice, or which has been left to spoil or expire as a result of negligence by the actor - predominantly, but not exclusively the final consumer at household level" [26].

FLW take place all along the food chain, ranging from the production and pre-harvest up to the consumer stage, on multiple levels and as a result of heterogeneous causes that vary significantly among world's countries. What is important to point out in this context is that FLW entail negative effects on each pillar of sustainable development - economic, environmental and social - at the micro (i.e. individual household or enterprise), meso (i.e. production chain) and macro (i.e. society) levels. From an economic perspective, FLW is considered by FAO as a global economic negative externality [27] and the associated direct economic costs are estimated around 1 trillion USD. If externalities, social and environmental costs are further weighed, another 1.6 billion USD would have to be added to the figure [28]. Moreover, FLW, as an expression of the inefficiency of food systems, results in higher food prices for consumers as well as in less effective programming and investment - both public and private (e.g. to enhance agricultural production, a key element for poverty reduction in developing countries).

In relation to the environmental impacts of FLW, the first aspect to be considered is the ineffective use of scarce resources - such as land and water - as well as all inputs that are required to produce the food that is lost or wasted. Additionally, the footprints of transport, packaging, processing, distribution and preparation at home eventually sum to the aforementioned dissipation, depending on which stage of the food chain FLW happen: that is why a foodstuff wasted at the consumer stage will entail a greater environmental impact than if the same foodstuff is loss during, for example, the harvest. Finally, another negative effect on the environment occurs during the waste disposal phase through methane emissions that lead to a significant carbon footprint: it is estimated that globally FLW is responsible for 6 up to $10 \%$ of anthropogenic greenhouse gas emissions [29], contributing considerably to climate change.

FLW negatively affects societies. Greenhouse gases emissions, resource depletion and pollution from agriculture potentially translate into health costs - born both at the individual and societal levels. As previously mentioned $80 \%$ of the world's poorest live in rural areas and rely on agricultural activities for income generation [30]: it is therefore worth noting that environmental degradation is extremely interlinked with poverty as the rural poor are more dependent on natural resources as well as more exposed to environmental threats and degradation. More broadly, FLW also increase food security risks, loss of livelihoods, likelihood of civil conflict and increases crime due to resource depletion, or loss of well-being and societal value due to loss of habitat and landscape amenities or species extinction with related existence value losses. Developing countries are typically characterised by a high volume of food losses - e.g. due to limited financial, managerial and technical capacities, poor infrastructure or inadequate storage facilities. This has a direct, negative impact on labour productivity and therefore on wages which, in turn, might diminish consumption levels whose increase is instead a crucial factor for rural development and ultimately for poverty reduction. 
Against this backdrop, a decrease in FLW would generate positive impacts on the aforementioned pillars. Nevertheless, it is important to point out that the ideal balance for sustainability is not zero food loss and waste, as beyond a certain point, the additional costs to further reduce or totally eliminate FLW might overtake the economic, social and environmental benefits generated by the reduction. The first key message within the context of this paper is that FLW must be substantially reduced; the second is that the residual FLW - result of the ideal point of equilibrium between costs and benefits - can be further used as a resource in circular economy models.

\section{From Linear to Circular Economy}

In a business-as-usual scenario, both the food and textile industries will have to deal with scarcity and depletion of key resources, as the current production and consumption patterns cannot be sustained on the long term. As a consequence, there is a compelling need to move away from the linear "take-make-dispose" system and shift to a circular approach focused on greater recycling, restorative, and transformative strategies. What is considered as a waste in a linear model becomes a resource in the context of a circular economy. Therefore, the loop is closed, ensuring that all resources are used as efficiently as possible.

In the last years, brands, investors, industry initiatives, and policy makers have shown a growing interest in circular economy models. In 2015, the European Union adopted the Circular Economy Action Plan, establishing a set of actions to facilitate and promote the transition to a system "where the value of products, materials and resources is maintained in the economy for as long as possible, and the generation of waste minimised". To better reflect the Union's ambition to move to a circular economy, reduce the EU's dependence on the import of raw materials, promote a prudent, efficient and rational use of natural resources, a revised legislative framework on waste entered into force in July 2018, amending the European Waste Framework Directive [31] (2008/98/EC). The main aim of the new piece of legislation is to ensure that valuable material embedded in waste is effectively re-used, recycled and reinjected into the European economy. In addition, the Directive [32] (EU) 2018/850 on the landfill of waste requires Member States to reduce the share of municipal waste landfilled to $10 \%$ by 2035 , and the Directive [33] (EU) 2018/852 on packaging waste introduces targets for the recycling $60 \%$ of all packaging by 2025 and $70 \%$ by 2030 . Food waste prevention and reduction are specifically included among the priority areas of the Circular Economy Action Plan. In addition, the new Framework Directive (EU) 2018/851 on waste, in line with the Goal 12.3 of the 2030 Agenda for Sustainable Development, sets an indicative Union-wide food waste reduction target of $30 \%$ by 2025 and $50 \%$ by 2030 .

Against this background, in order to support informed decisions for more sustainable restorative strategies, it is relevant to recall the distinction between waste and by-products. Indeed, industrial production processes are often complex and can generate several outputs with different economic values, environmental and social impacts. The waste/non-waste status is crucial to the exploitation of the material concerned as well as for the enactment of the strict norms regulating waste management, disposal, transportation, treatment, and end-of-waste process - which, in turn, impact on costs.

The by-products category was first introduced by Waste Framework Directive in 2008, according to a waste prevention approach. Article 5 provides for a definition of by-products and the main conditions which must be cumulatively met by a substance or object to be classified as such, namely:

a. Further use of the substance or object is certain;

b. The substance or object can be used directly without any further processing other than normal industrial practice;

c. The substance or object is produced as an integral part of a production process; and

d. Further use is lawful, i.e. the substance or object fulfils all relevant product, environmental and health protection requirements for the specific use and will not lead to overall adverse environmental or human health impacts

In recent jurisprudence, (Palin Granit and following cases) the ECJ has further elaborated on such definition and set out a three-part test that a production residue must meet in order to be considered as a by-product. The court stated that where the further use of the material was not a mere possibility but a certainty, without any further processing prior to reuse and as part of a continuing process of production, then the material would not be a waste. These requirements are cumulative - all three must be met. In addition to this test, the ECJ has noted that the use for which the by-product is destined must also be lawful - in other words that the by-product is not something that the manufacturer is obliged to discard or for which the intended use is forbidden under EU or national law (EU Commission, by-products).

The consequences of such a qualification can vary from sector to sector: in general terms, an incorrect classification could be the cause of environmental damage or unnecessary costs for business.

Although for food and drinks the distinction between waste and non-waste products must be drawn strictly in order to ensure food safety, promoting a legislative environment prioritising the classification of substances as products and not as waste should help to allow more materials to remain product or be classified as by-product and thereby protect their value.

As operators of the agri-food and fashion sectors are keen on identifying new business opportunities and on ensuring an efficient use of resources, industrial biotechnology does already offer effective strategies and tools for keeping such resources in the system, including the sourcing of synthetic fibres from by-products and waste of the food industry. However, despite relevant advances, 
the potential of food waste and by-products to create new business opportunities, as well as the following the extraction of valuable compounds still seems under-estimated by the new EU framework [34].

Clarifying the abovementioned rules would further facilitate cross-industrial synergies, following systemic life cycle thinking In addition, consistent policy implementation in EU Member States needs to be ensured, especially regarding the "waste" or "nonwaste" status given to some products, as different regulations hamper the realisation of the circular economy in the European internal market. Consistency between all policies ensuring an integrated approach, regular updates to keep up with technical progress should therefore be reached to further boost the circular economy.

\section{Edible Innovations: Today's Trash, Tomorrow's Treasure}

With fashion brands seeking more sustainable innovations and bio-materials, it is no wonder that envisioning a new life for food waste as a resource for the apparel sector appears as a promising opportunity for both industries. This kind of recycling is not strictly speaking "closing the loop", within the boundaries of the food industry, but is "open loop" recycling where, under the principles of industrial ecology, a waste stream from one activity becomes the source of materials for another [35]. The advantages are twofolded: on the one hand, turning trash into a resource solves the waste disposal problem, improves waste management practices, and increases resource efficiency, limiting the use of landfilling On the other hand, recycled and innovative fibres do not require any extra farmland, water, fertilisers or pesticides to produce. In addition, involvement in sustainability initiatives can serve as a real source of brand differentiation: from new product development to innovative campaigns, more-sustainable solutions seem increasingly attractive for a growing customer base, and especially among Millennial [36].

Many technologically sophisticated methods of treating food waste and by-products to produce fibres are already in commerce, with other waste-derived creations on the horizon. One of the most prominent examples is represented by Orange Fiber, the first fabric in the world made with cellulose extracted from the by-product of citrus juice production. Adding value to waste not only entails lower environmental footprints, but also generates an additional stream of income for rural communities. This is the case for Piñatex, an innovative leather-like material made from the pineapple leaf fibre by Ananas Anam, a by-product of the fruit industry which is traditionally discarded or burned [37].

It is worth noting that even the world's second biggest producer of disposable fashion products, $\mathrm{H} \& \mathrm{M}$, relied on the abovementioned materials for its last Conscious Exclusive capsule. Despite the limited number of premium pieces, this collection has the merits to showcase the increasing possibilities of mainstreaming innovative fibres, through beautiful garments at affordable prices. The fast fashion brand built upon the fact that sustainability is seen by customers as an add-on, and addressed the main barriers preventing them from purchasing sustainable fashion: lack of knowledge and visibility of new materials, the high price attached to "green" garments and limited style [38].

It becomes clear, thus, that focusing on the ethical and sustainable mix of core values is a good starting point, but it is not enough, as other drivers are needed. One of these is undoubtedly functionality, which is the main asset of S.Café, a yarn created by combining coffee grounds with polyester obtained from discarded plastic bottles and patented by the Taiwanese company Singtex [39-50]. The resulting material - which can already be found in a number of products from leading fashion companies - is multifunctional and can be suitable for a variety of uses, from outdoor and sportswear to household items. The coffee grounds used to create the yarn are recycled from some of the world's largest coffee vendors, like Starbucks, as well as from local coffee shops. In addition, garments made from S.Café can also be composted at the end of their life, giving them a circular lifecycle.

Other small-scale initiatives using advanced technologies can be an important launching pad for experimentation. A recent example is the use and valorisation of casein through a bio-recycling system which relies on industrial, dairy and cosmetic low value by-product. Drawing from an Italian invention dating back to the '30s, and with the support of research and innovation, Duedilatte started to produce a new fibre characterized by moisturizing properties which ensure skin protection and hydration. Its original value proposition lies in transforming milk waste in a lever for wellbeing, while capitalizing on the adoption of natural ingredients and innovative bio-production processes. The product, thus, targets a new consumer segment looking for a healthy and natural goods, particularly suitable for new-born [51-70].

Another case is that of Blue Fashion, which illustrates the combined use of drivers such as up cycling, local sourcing, community collaboration, and artisan crafts. The business model focuses on the use of fish skin, a by-product of the fishing industry, to develop sustainable leather made from fish caught in one of the poorest rural areas of the world, Lake Turkana. Kenya's northernmost region can count on skilled "skinners", whose livelihood could be strengthened, while reducing waste and offering sustainable alternatives to the fashion industry, though the innovative fish skin material [70-80]. Such potential was recognized by FAO, which partnered with the Nordic Atlantic Cooperation and the Commonwealth Fashion Council on a Blue Fashion show that unveiled signature realized with Kenyan fish leather by African fashion designers. Drawing from the locally sourced driver, huge potential in Kenya and the neighbouring countries, offering higher prices to the fishers and creates alternative local employment for the community [81-90].

\section{Conclusion}

So far, the relation between the textile and food industries has been pictured in negative terms, with a strong focus on trade-offs 
rather than positive interactions. Quite the contrary, more recent developments show that cross-industry collaboration can lead to regenerative impacts, originally recombining different approaches, resources, and competencies with synergic effects. As provided for by SDG 17, a successful sustainable development agenda requires partnerships built upon principles and values, a shared vision and goals that place people and the planet at the centre. The joint efforts outlined above are moving in this direction, and seem particularly encouraging given that the textile and food industries are tackling similar challenges in a number of impact areas along their value chains, from raw material production to end-of-life disposal [91$100]$.

Within this process, main challenges still need to be addressed.

A stronger legislative commitment on optimisation and reuse of resources is needed, to allow new business models to emerge and to enhance the competitiveness of both the textile and agrifood value chains, as well as resource savings. The drive to foster circular economy should also lead to a business environment where sustainable production initiatives can be measured and compared to each other with the help of a harmonised methodology and upto-date data [101].

At the same time, research and innovation should be fostered and encouraged, to boost the circular approach by generating new ideas and by scaling up existing ones. This, in turn, will require supportive actions to scaling up innovations and facilitate the establishment of collaborative efforts, connecting incumbents and start-ups within an open innovation framework. Indeed, while the former are relatively effective in establishing competitive advantages but less able to identify new opportunities and change accordingly, the latter are inherently more innovative but less successful in developing competitive advantages needed to appropriate value from those innovations. A starting point for shared commitments could be experimenting with small-scale initiatives focusing on sustainability and addressing structural issues, such as promoting transparency and innovation in raw material management. Such pilot projects would drive down costs and enable the magnitudes necessary to scale up to commercial viability [102].

Furthermore, regulators can motivate and amplify the moves of farsighted companies, for instance, with incentives. Going further, governments could push the technological frontier with public research grants or subsidies on company- or industry-wide R\&D. Combining the top-down and bottom-up approaches can foster best practices across all industry segments and reinforce the implementation of rules within agreed targets, encouraging the shift from voluntary commitments to binding obligations. Moreover, a collective effort with critical mass would enable the industry to overcome the current lack of harmonization and make progress on a unified agenda, focusing time, energy and money on shared and consolidated goals [103].

Finally, there is a compelling need to boost consumers' information and education. Despite the fact that we live in a world of information, paradoxically, the society simultaneously suffers from a scarcity of "smart" data, i.e. information that is traceable and therefore reliable, trust-worthy, and ultimately verifiable. The potential of new technologies such as Internet of Things (IoT), Blockchain, 3D manufacturing as well as Artificial Intelligence - embodied in smart labels or apps - should further be explored to facilitate increased transparency of the production chain and traceability of materials.

In light of the above, it becomes clear that taking innovations global, fostering cross-industry collaboration and encouraging supporting regulatory action may open up new - and more sustainable - opportunities for business, tackling the pressures of resource scarcity. Today's scattered, and fragmented array of initiatives, collaborative cross-industry approaches appear as promising but consolidation is inevitable to focus time, energy and money. The joint efforts of the food and fashion sectors an agenda for change, could drive the needed systemic change and work jointly on disruptive innovation.

\section{Acknowledgement}

None.

\section{Conflict of Interest}

None.

\section{References}

1. Sachs J, Schmidt-Traub G, Kroll C, Lafortune G, Fuller G (2018) SDG Index and Dashboards Report 2018. New York: Bertelsmann Stiftung and Sustainable Development Solutions Network (SDSN).

2. Steffen W, Richardson K, Rockströmet J, Cornell SE, Fetzer I, et al. (2015) Planetary Boundaries: Guiding Human Development on a Changing Planet. Science 347(6223): 1259855-1259855.

3. Rockström J, Steffen W, Noone K, Persson Å, Chapin FS, et al. (2009) Planetary boundaries: exploring the safe operating space for humanity. Ecology and Society 14(2): 32.

4. Simpson P (2016) Global Trends in Fibre Prices, Production and Consumption. Textile Outlook International 179: 75-92.

5. Fletcher K, Vitters $\varnothing$ G (2018) Local Food Initiatives and Fashion Change: Comparing Food and Clothes to Better Understand Fashion Localism. Fashion Practice 10(2): 160-170.

6. Vitters $\varnothing$ G, Kjærnes U, Austgulen MH (2015) Sustainable Consumption in the Norwegian Political Economy of Beef, in The Consumer in Society: A Tribute to Eivind Stø. Strandbakken P, Gronow J (edts), pp. 267-290.

7. Annamma J, Sherry JF, Venkatesh JA, Wang J, Chan R (2012) Fast Fashion, Sustainability, and the Ethical Appeal of Luxury Brands. Fashion Theory 16(3): 273-296.

8. Ritzer G (2011) The McDonaldization of Society, (6 ${ }^{\text {th }}$ edn) Newbury Park, CA: Pine Forge Press, USA.

9. EU Commission Staff Working Document (2012) Where manufacturing meets creativity, SWD 271.

10. EU Commission Staff Working Document (2017) Sustainable garment value chains through EU development action, SWD 147.

11. Friedman V (2018) The Biggest Fake News in Fashion, The New York Times.

12. FAO (2018) \#BlueFashion: From Lake Turkana to the runway Promoting a sustainable blue economy to support livelihoods in Kenya. 
13. European Commission - Joint Research Centre - Institute for Environment and Sustainability (2010) International Reference Life Cycle Data System (ILCD) Handbook - General guide for Life Cycle Assessment - Detailed guidance. First edition. EUR 24708 EN. Luxembourg, UK.

14. UNEP, SETAC (2009) Guidelines for Social Life Cycle Assessment of Products.

15. McKinsey Company, Business of Fashion (2019) The State of Fashion 2019.

16. Global Fashion Agenda and The Boston Consulting Group (2018) Pulse of the Fashion Industry Report 2018.

17. Kering BS (2017) Climate Change: Implications and Strategies for the Luxury Fashion Sector

18. Changing Markets Foundation (2018) Dirty Fashion Revisited Spotlight on a polluting viscose giant.

19. Ellen MacArthur Foundation (2017) A new textiles economy: Redesigning fashion's future.

20. IUCN (2016) Biodiversity Risks and Opportunities in the Apparel Sector.

21. Laitala K, Klepp IG, Henry B (2018) Does Use Matter? Comparison of Environmental Impacts of Clothing Based on Fiber Type. Sustainability 10: 2524

22. IUCN (2017) Primary Microplastics in the Oceans: a global evaluation of sources.

23. FAO (2018b) The state of food security and nutrition in the world. Rome: FAO

24. FAO, IFAD and WFP (2015) Achieving Zero Hunger: the critical role of investments in social protection and agriculture. Rome: FAO.

25. FAO (2017) The future of food and agriculture - Trends and challenges. Rome: FAO

26. FAO (2014a) SAVE FOOD: Global Initiative on Food Loss and Waste Reduction - Definitional framework of food loss. Working Paper. Rome FAO.

27. FAO (2013) The State of Food Insecurity in the World. Rome: FAO.

28. FAO (2014b) Food Wastage Footprint: Full-Cost Accounting. Rome: FAO.

29. Vermeulen S, Campbell B, Ingram S (2012) Climate change and food systems. Annual Review of Environmental Resources 37: 195-222.

30. World Bank. (2016). High and dry: climate change, water, and the economy. Washington, DC: World Bank, USA.

31. Directive (EU) 2018/851 of the European Parliament and of the Council of 30 May 2018 amending Directive 2008/98/EC on waste.

32. Directive (EU) 2018/851 of the European Parliament and of the Council of 30 May 2018 amending Directive 2008/98/EC on waste.

33. Directive (EU) 2018/852 of the European Parliament and of the Council of 30 May 2018 amending Directive 94/62/EC on packaging and packaging waste.

34. European Food Sustainable Consumption \& Production Round Table (2018) Enhancing the contribution of the agri-food value chain to the circular economy.

35. Greenpeace international (2017) Fashion at the Crossroads

36. Remy N, Speelman E, Swartz S (2019) Style that's sustainable: A new fast-fashion formula, McKinsey.

37. (2019) Ananas Anam, Pinatex

38. Porter JR, Xie L, Challinor AJ, Cochrane K, Howden SM, et al. (2014) Food security and food production systems. In IPCC. 2014. Climate Change 2014: Impacts, adaptation, and vulnerability. Part A: Global and sectoral aspects. Contribution of Working Group II to the Fifth Assessment Report of the Intergovernmental Panel on Climate Change, Cambridge, UK; New York: Cambridge University Press, pp. 485-533.
39. Alexandratos N, Bruinsma J (2012) World agriculture towards 2030/2050: the 2012 revision. ESA Working Paper No. 12-03. Rome: FAO

40. Bariber EB (2010) Cash Crops, Food Crops and Agricultural Sustainability, International Institute for Environment and Development, Gatekeeper Series No. 2

41. Boucher J, Friot D (2017) Primary Microplastics in the Oceans: A Global Evaluation of Sources. Gland, Switzerland: IUCN.

42. Buzby JC, Wells HF, Hyman J (2014) Estimated food loss at the retail and consumer levels in the United States. Economic Information Bulletin, No. 121. Washington DC: USDA.

43. Fletcher K (2010) Slow Fashion: An Invitation for Systems Change. Fashion Practice 2(2): 259-265.

44. Jaramillo F, Destouni G (2015) Comment on "Planetary boundaries: Guiding human development on a changing planet". Science 348(6240): 1217

45. Jorgen R, Rockström J, Stoknes PE, Goluke U, Collste D, et al. (2018) Achieving the 17 Sustainable Development Goals Within 9 Planetary Boundaries in EarthArXiv. Web

46. Ligon E, Sadoulet E (2007) Estimating the effects of aggregate agricultural growth on the distribution of expenditures. Washington DC: World Bank

47. Muthu S (2017) Sustainable Fibres and Textiles. Woodhead Publishing, UK.

48. O’Neill DW, Fanning AL, Lamb WF, Steinberger JK (2018) A good life for all within planetary boundaries. Nature Sustainability 1(2): 88-95.

49. Roos S, Sandin G, Zamani B, Peters G (2015) Environmental assessment of Swedish fashion consumption. Five garments - sustainable futures, Mistra Future Fashion Consortium

50. Smil V (2008) Energy in nature and society- general energetic of complex systems. Cambridge: MIT Press, USA.

51. Szmydke-Cacciapalle P (2018) Making Jeans Green: Linking Sustainability, Business and Fashion, Routledge.

52. Business and Sustainable Development Commission (2017) Better business Better World. London.

53. Carbon Trust (2018) Three sustainability trends shaping the future of the fashion industry.

54. Clean Clothes Campaign (2014) Stitched up: poverty wages for garment workers in Eastern Europe and Turkey. Clean Clothes Campaign.

55. Clean Clothes Campaign (2014) Living wage in Asia. Amsterdam: Clean Clothes Campaign.

56. Clothing Sustainability Research Group, Nottingham Trent University (2018) Sustainability of the fashion industry inquiry: Written evidence submitted by Professor Tim Cooper, (SFI0049).

57. Ellen MacArthur Foundation (2019) New Plastics Economy Global Commitment

58. Ethical Trading Initiative, Hult International Business School (2016) Corporate Leadership on Modern Slavery. Summary Report.

59. European Commission (2017) Sustainable garment value chains through EU development action. Staff Working Document.

60. FAO (2011a) The State of Food and Agriculture, Women in Agriculture - Closing the gender gap for development. Rome: FAO.

61. FAO (2011b) The state of the world's land and water resources for food and agriculture (SOLAW) - Managing systems at risk. Rome: Food and Agriculture Organization of the United Nations; London: Earth scan.

62. FAO (2011c) Global food losses and food waste. Extent, causes and prevention. Rome. FAO.

63. FAO (2015) Global Forest Resources Assessment 2015. Rome: FAO

64. FAO (2016) Food and Agriculture - Key to achieving the 2030 Agenda for Sustainable Development. Rome: FAO. 
65. FAO (2018a) Sustainable Food Systems - Concept and Framework. Rome: FAO.

66. FAO \& USAID (United States Agency for International Development) (2015). Opportunities for agri-food chains to become energy-smart Rome: FAO.

67. Global Fashion Agenda (2018) CEO Agenda. Seven sustainability priorities for fashion industry leaders.

68. Global Fashion Agenda and The Boston Consulting Group (2017) Pulse of the Fashion Industry Report 2017.

69. HLPE (2014) Food losses and waste in the context of sustainable food systems. A report by the High Level Panel of Experts on Food Security and Nutrition of the Committee on World Food Security, Rome 2014.

70. ILO Regional Office for Asia and the Pacific (2015). Employment, wages and working conditions in Asia's Garment sector: Finding new drivers of competitiveness. ILO Asia-Pacific working paper series.

71. ILO Regional Office for Asia and the Pacific (2016). Weak minimum wage compliance in Asia's garment industry. ILO Asia-Pacific Garment and Footwear Sector Research Note.

72. IMF (2017) World Economic Outlook, Seeking Sustainable Growth: Short-Term Recovery, Long-Term Challenges.

73. McKinsey Company, Business of Fashion (2019) The State of Fashion 2018.

74. QUANTIS (2018) Measuring Fashion. Environmental Impact of the Global Apparel and Footwear Industries Study.

75. UN (2016) 2014 Energy Statistics Yearbook. New York: United Nations.

76. UN (2016) The First Global Integrated Marine Assessment, World Ocean Assessment Report. New York: United Nations.

77. UN (2018) The Sustainable Development Goals Report. New York: United Nations.

78. UNEP (2016) Marine plastic debris and microplastics - Global lessons and research to inspire action and guide policy change. United Nations Environment Programme, Nairobi.

79. UNFCC (under the auspices of) (2018) Fashion Industry Charter for Climate Action. Katowice, Poland.

80. World Bank (2016) Poverty and shared prosperity - tacking on inequality. Washington DC: World Bank Group.

81. WRAP (2017) Valuing Our Clothes: the cost of UK fashion.
82. Communication from the Commission to the European Parliament, the Council, the European Economic and Social Committee and the Committee of the Regions. Closing the loop - An EU action plan for the Circular Economy. COM/2015/0614

83. Directive 2008/98/EC of the European Parliament and of the Council of 19 November 2008 on waste and repealing certain Directives.

84. UN General Assembly (2015) Transforming our world: the 2030 Agenda for Sustainable Development. A/RES/70/1

85. (2016) EU Commission, By-products.

86. Greenpeace (2016) Fast fashion is "drowning" the world. We need a Fashion Revolution!

87. H\&M (2019) H\&M Conscious Exclusive.

88. Making Climate Change Fashionable - The Garment Industry Takes On Global Warming, in Forbes.

89. Petruzziello M (2015) 5 things you probably didn't know about the fashion industry, World Economic Forum.

90. Shannon S (2017) Fast Fashion Slow to E-Commerce. Business of Fashion.

91. WWF (2013) The Impact of a Cotton T-Shirt. Retrieved from: https:// www.worldwildlife.org/stories/the-impact-of-a-cotton-t-shirt

92. WWF (2013) Thirsty Crops: Our food and clothes: eating up nature and wearing out the environment?

93. WWF (2016) The Impact of a Cotton T-Shirt.

94. (2010) Columbia Edu, The Aral Sea Crisis.

95. European Commission (2016) Food waste.

96. (2010) International Wool Textile Organisation, Wool \& the Environment.

97. Kering (2018) Environmental Profit \& Loss

98. Oakdene Hollins Limited. (2018) Fabric Database - Polyester.

99. (2010) Reformation, Ref Scale.

100. (2019) UN Fashion Alliance.

101. (2029) Orange FIber

102. Salvatore Ferragamo (2019) Orange Fiber. Green Fashion Inspiration.

103. Singtex (2019) S Café. 